\title{
Mathematical Approach to Determination of Optimum Oil Production Rate in Oil Rim Reservoirs
}

\author{
Obibuike Ubanozie Julian, Ekwueme Stanley Toochukwu*, Ohia Nnaemeka Princewill, \\ Igwilo Kevin Chinwuba, Igbojionu Anthony Chemazu, Kerunwa Anthony
}

Department of Petroleum Engineering, Federal University of Technology, Owerri (FUTO), Nigeria

\section{Email address:}

stanleyekwueme@yahoo.com (S.T. Ekwueme)

${ }^{*}$ Corresponding author

\section{To cite this article:}

Obibuike Ubanozie Julian, Ekwueme Stanley Toochukwu, Ohia Nnaemeka Princewill, Igwilo Kevin Chinwuba, Igbojionu Anthony Chemazu, Kerunwa Anthony. Mathematical Approach to Determination of Optimum Oil Production Rate in Oil Rim Reservoirs. Petroleum Science and Engineering. Vol. 3, No. 2, 2019, pp. 60-67. doi: 10.11648/j.pse.20190302.14

Received: September 28, 2019; Accepted: October 25, 2019; Published: November 11, 2019

\begin{abstract}
Oil rim reservoirs present unique problems during production. This is because of the proximity of the water and/or gas to the oil in the pay zone leading to phase distortion due to pressure disequilibrium during production of the oil. The resultant effect is early water/gas breakthroughs which ultimately lead to increased well operational cost, damage to production equipment and eventually to early loss of the well. Production rate becomes crucial as it directly or indirectly affects the overall recovery efficiency from the well. Low rate production signifies longer well production period due to delayed breakthrough time but at the expense of higher well operational cost per unit volume of oil produced, while higher rate production signifies higher oil volume per unit cost of well operation but with increased risk of losing the well due to water/gas breakthrough. Operators produce at a rate deemed economic in order to make profits. Most economic rates are higher than the critical rate which is the rate considered that coning would be maximally delayed. To optimize production, it is necessary to recover most of the fluid from the reservoir before abandonment. Higher recovery factors means that less volume of fluid is left in the reservoir at abandonment. The optimum oil production rate is the best economic oil rate that would result to the highest recovery factor obtainable from that well. The question is what rate is considered optimal and how can it be calculated? This work presents a mathematical model solution for the calculation of the optimum oil production rate. It takes cognizance of the recovery factor and the time value of money and present an analytical model to calculate the optimum oil production rate. From the work the optimum oil production rate was calculated to be $918.63 \mathrm{stb} / \mathrm{d}$ while the critical oil rate was calculated to be $20.17 \mathrm{stb} / \mathrm{d}$.
\end{abstract}

Keywords: Oil Rim, Optimum Oil Rate, Coning, Economic Rates

\section{Introduction}

An Oil rim reservoir is a reservoir with small oil columns. Most of the oil rim reservoirs are sandwiched between an overlain gas cap and an underlain aquifer. Producing from oil rim reservoirs has always been a challenge in the Oil and Gas Industry [1-3]. The threat of producing oil rim reservoirs comes from the strategic location of the oil in relation to the other reservoir fluids which pose serious operational and economic challenges using existing conventional methods of optimizing reservoir development. The presence of a wide range of uncertainty, the peculiar complexity in the distribution of the resident fluids and geological strata geometry, have made efficient development and production of thin oil column a difficult task $[4,5]$.

Water and gas coning are the problems encountered in producing from oil rim reservoirs, where the production of water and gas from an oil rim reservoirs are common occurrence, which increase the cost of production, and reduce the efficiency of the depletion mechanisms and the overall recovery. One of the main reasons for coning is pressure drawdown [6-8]. A vertical well exhibits a large pressure drawdown near the wellbore, whereas horizontal well exhibits minimum pressure drawdown, thus horizontal wells provide option whereby pressure drawdown can be 
minimized, coning tendencies can be minimized, and high oil production rates can be achieved. Two forces control the mechanism of water coning: (1) dynamic flow force (applied force), and (2) gravity force [9].

One of the techniques used to solve coning problem was to let the oil to be produced at a sufficiently low rate, such that coning of water and gas can be avoided, and only oil is produced. This low rate is called critical oil rate. The critical oil rate is defined as the maximum water-free production rate. Different theoretical correlations conflict and give different answers, probably due to the different assumptions which they consider, and many times the critical rates are too low, and for economic reasons, a well is frequently produced in field operations at a rate above critical rate. This results in production of water, gas as well as oil, which could result to low economic recovery. To overcome this problem, an extensive parametric sensitivity analysis of the various reservoir and fluid properties on water and gas coning was investigated and performed using numerical simulation to provide input data for developing a new predictive correlation needed to calculate breakthrough time and optimum oil rate based on optimizing economic recovery for both vertical and horizontal wells [10-12].

Optimizing recovery in this sense entails that the well be produced at the best and most optimal production rate. This requires first, the knowledge of the critical production rate, the economic rate, the breakthrough time for the economic rate. Note that in most cases the optimal recovery rate falls between the critical rate and the maximum recoverable rate for that well. Optimization in this sense is necessary because the critical rate is usually not economical and producing at very high rates leads to early fluid breakthrough which also leads to high production cost or early abandonment of the well, thereby leaving behind large volumes of oil in the reservoir $[13,14]$. In view of this, a balance must be created between the cost of production (which is a function of years of production before abandonment), the volume of fluid recovered (which is a function of the production rate), and volume of fluid left in the reservoir as a result of abandonment due to coning [15].

\subsection{Description of Terms}

a) The Critical Oil Rate: this is the maximum oil production rate without the concurrent production of the displacing fluid phase by coning. The displacing fluid phase could be water or gas or both.

b) The Breakthrough Time: this is the time from the onset of production to the time the first displacing fluid arrives at the perforated intervals.

c) The Economic Oil Rate: this is the production rate for which the project becomes economically feasible. Most critical rate are not economical, that is to say that they do not yield economic volumes of fluid to offset the production expenses when measured daily or annually. Thus economic rates are usually higher than the critical oil rates to enable the company to make profit. Usually when the well is produced at higher rates than the critical rate then cones are expected to form earlier. When this happens, the displacing fluid will be produced causing additional production expense to cater for the displacing phase production. Thus, if you produce at a low rate, you are not maximizing profit and if you produce at a very high rate you will incur additional production expenses and might lose the well at an earlier time. The interest now is to calculate the rate that will not be too low such that profit would be maximized and would not be too high to incur greater additional production and expense coupled with early abandonment of well. This rate is what we term the optimal oil production rate.

d) The Optimum Production Rate: This is the rate that will yield the highest revenue throughout the life of the well.

e) The Lifting Cost: This is the cost of producing one barrel of crude from the well to the surface stock tank. It is expressed in dollars annually or daily. For the sake of simplicity, the lifting cost can be expressed in stock tank barrels (STB) of fluid produced. Thus mathematically:

Total fluid recovered (Stb) - lifting cost (Stb)

$$
=\text { total revenue }(\mathrm{Stb})
$$

f) The Abandonment Volume: this is quantity of oil left in the reservoir when the reservoir is considered not economically viable for continued production. In this case, the revenue from production is below economic margin when compared to the production expenses.

\subsection{Assumptions}

i) The well is produced until breakthrough occurs and the well is abandoned. ii) the reservoir is finite, iii) the well is vertical iv) constant annual operating cost.

\subsection{Equations Used in Coning Models}

There are several established equations for coning available in literatures, they describe factors such as critical oil rate, breakthrough time etc. Some of the models are described below for vertical and horizontal wells.

\subsubsection{Critical Oil Rate Equation}

Several models have been developed for the critical oil rate. Some are for vertical wells while others are for horizontal wells.

1. Critical oil rate for vertical wells

For the sake of this work, the Chaperson model for critical oil rate shall be used. The equation is stated as follows

$$
Q_{O C}=0.0783 \times 10^{-4} \frac{K_{h}\left(h-h_{p}\right)^{2}[\Delta \rho] q_{C}^{*}}{\mu_{o} \beta_{o}}
$$

Where: $\mathrm{Q}_{\mathrm{oc}}=$ critical oil rate, STB/day, $\mathrm{k}_{\mathrm{h}}=$ horizontal permeability, md, $\Delta \rho=\rho_{\mathrm{w}}-\rho_{\mathrm{o}}$, density difference, $\mathrm{lb} / \mathrm{ft}^{3}, \mathrm{~h}=$ oil column thickness, $\mathrm{ft}, \mathrm{h}_{\mathrm{p}}=$ perforated interval, $\mathrm{ft}$

And

$$
q_{c}^{*}=0.7311+\left(1.943 / \alpha^{\prime \prime}\right)
$$




$$
\alpha^{\prime \prime}=\left(r_{e} / h\right) \sqrt{k_{v} / k_{h}}
$$

2. Critical Oil Rate for Horizontal Wells

The Chaperson model for coning in horizontal well is given as follows

i. For water coning

$$
Q_{O C}=0.0783 X 10^{-4}\left[\frac{L q_{c}^{*}}{y_{e}}\right]\left(\rho_{w}-\rho_{o}\right) \frac{K_{h}\left[h-\left(h-D_{b}\right)\right]^{2}}{\mu_{o} \beta_{o}}
$$

ii. For gas coning

$$
Q_{O C}=0.0783 \times 10^{-4}\left[\frac{L q_{c}^{*}}{y_{e}}\right]\left(\rho_{o}-\rho_{g}\right) \frac{K_{h}\left[h-\left(h-D_{t}\right)\right]^{2}}{\mu_{o} \beta_{o}}
$$

The above two equations are applicable under the following constraint:

$$
1 \leq \alpha^{\prime \prime}<70 \text { and } 2 \text { ye }<4 \mathrm{~L}
$$

\subsubsection{Breakthrough Time Equation}

i. Breakthrough time equation for vertical well

We use The Sobocinski-Cornelius Method

$$
t_{B t}=\frac{20325 \mu_{o} h \phi\left(t_{D}\right)_{B T}}{\left(\rho_{w}-\rho_{o}\right) k_{v}\left(1+M^{\alpha}\right)}
$$

Where: $t_{B t}=$ time to breakthrough, days, $\phi=$ porosity, fraction, $\mathrm{kv}=$ vertical permeability, $\mathrm{md}, \mathrm{M}=$ water-oil mobility and is defined by:

$$
M=\frac{\left(K_{r w}\right)_{s o r}}{\left(K_{r o}\right)_{s w c}}\left(\frac{\mu_{o}}{\mu_{w}}\right)
$$

With

$(\mathrm{kro}) \mathrm{swc}=$ oil relative permeability at connate water saturation

$(\mathrm{krw})$ sor $=$ water relative permeability at residual oil saturation

$$
\begin{gathered}
\left(t_{D}\right)_{B T}=\frac{4 Z+1.75 Z^{2}-0.75 Z^{3}}{7-2 Z} \\
Z=\frac{0.492 \times 10^{-4}\left(\rho_{w}-\rho_{o}\right) K_{h} h\left(h-h_{p}\right)}{\mu_{o} \beta_{o} Q_{o}}
\end{gathered}
$$

Where: $\rho=$ density, $\mathrm{lb} / \mathrm{ft}^{3}, K_{h}=$ horizontal permeability, $\mathrm{md}, Q_{o}=$ oil production rate, $\mathrm{STB} /$ day, $h_{p}=$ perforated interval, $\mathrm{ft}, h=$ oil column thickness, $\mathrm{ft}$

ii. The breakthrough time equation for Horizontal well

We used the Papatzacos' Method for calculating breakthrough time for horizontal well

The breakthrough time $t_{B t}$ is given by

$$
\begin{gathered}
t_{B t}=\frac{22,758.528 h \phi \mu\left(t_{D}\right)_{B T}}{\left(\rho_{w}-\rho_{o}\right) k_{v}} \\
\left(t_{D}\right)_{B T}=1-\left(3 q_{D}-1\right) \ln \left(\frac{3 q_{D}}{3 q_{D}-1}\right)
\end{gathered}
$$

And

$$
q_{D}=\frac{20,333.66 \mu_{o} \beta_{o} Q_{o}}{\operatorname{Lh}(\Delta \rho) \sqrt{k_{v} k_{h}}}
$$

$\Delta \rho=\left(\rho_{w}-\rho_{o}\right)$ for water coning

$\Delta \rho=\left(\rho_{o}-\rho_{g}\right)$ for gas coning

Where, $t_{B t}=$ time to water breakthrough as expressed in days, $\rho \mathrm{o}=$ oil density, $\mathrm{lb} / \mathrm{ft}^{3}, \rho \mathrm{w}=$ water density, $\mathrm{lb} / \mathrm{ft}^{3}, \rho=$ density, $\mathrm{lb} / \mathrm{ft}^{3}, \mathrm{kv}=$ vertical permeability, $\mathrm{md}, \mathrm{kh}=$ horizontal permeability, $\mathrm{md}, \mathrm{h}=$ oil zone thickness, $\mathrm{ft}, \mathrm{L}=$ length of horizontal well.

\section{Methods}

\subsection{Mathematical Model Development}

For us to model the scenario let us define some parametres

Let: $q_{r}=$ the desired oil production rate in $\mathrm{stb} / \mathrm{d}, t_{B t}=$ the break through time in years, $n=$ number of operational days in a year, usually 365 days, $\mathrm{C}=$ the lifting cost of oil expressed in $\mathrm{stb} / \mathrm{d}, P_{i}=$ profit per year realized before breakthrough in dollars

If we conduct a mathematical analyzed then the total profit realized for a given flowrate per year before breakthrough is given by

$$
P_{i}=n\left(q_{r}-C\right)
$$

For a 365 operational days per year, the equation becomes

$$
P_{i}=365\left(q_{r}-C\right)
$$
by

The total undiscounted profit before breakthrough is given

$$
P_{T}=P_{i} t_{B t}=n\left(q_{r}-C\right) t_{B t}
$$

To calculate the profit generated at the time of breakthrough, we shall consider the effect of time value of money and also the effect caused by revenue loss due to oil abandonment in the reservoir as a result of breakthrough.

$q_{T}=$ Oil production rate per year

$\mathrm{Q}=$ initial oil in place bbls

$\mathrm{I}=$ discount rate.

Since some of the oil will be abandoned after breakthrough, the recovery factor is given by

$$
\begin{gathered}
R F=\frac{\text { total volume of oil recovered }}{\text { Oil initially in place }} \\
R F=\frac{n q_{r} t_{B t}}{Q}
\end{gathered}
$$

Considering the time value of money, the profit from the onset of production to the time of abandonment (in years) is given by

$$
P_{E}=P_{T} R f x \text { time value of money }
$$

Where time value of money invested

$$
C_{T}=(1+i)^{-t_{B t}}
$$

Thus the equation is expanded to become

$$
P_{E}=\frac{P_{i} q_{T} t_{B t}^{2}(1+i)^{-t_{B t}}}{Q}
$$


But

$$
q_{T}=n q_{r}
$$

And

$$
P_{i}=n\left(q_{r}-C\right)
$$

Expanding further, the equation becomes

$$
\begin{aligned}
P_{E} & =\frac{n\left(q_{r}-C\right) n q_{r} t_{B t}^{2}(1+i)^{-t} t_{B t}}{Q} \\
P_{\mathrm{E}} & =\frac{\mathrm{n}^{2}\left(\mathrm{q}_{\mathrm{r}}-\mathrm{C}\right) \mathrm{q}_{\mathrm{r}} \mathrm{t}_{\mathrm{t}}^{2}(1+\mathrm{i})^{-\mathrm{t}_{\mathrm{Bt}}}}{\mathrm{Q}}
\end{aligned}
$$

Thus $P_{E}$ is called the discounted economic profit at the breakthrough time given in barrels.

Note that the value $P_{E}$ is only a relative value and not the absolute value as it helps us to know the value of the flowrate that would yield the greatest profit. The exact value of the profit is not that represented by the value $P_{E}$.

\subsection{The Optimal Oil Flowrate}

The value $P_{E}$ is a function of the oil production rate. The value continues to change for various oil rate chosen. First it begins to increase for increasing oil rate value until a certain value of oil rate for which the $P_{E}$ is maximum, and then continuous increment of the oil rate values yield lower values of $P_{E}$. The oil production rate that corresponds to the maximum $P_{E}$ is called the optimal oil production rate since it is the oil rate that yields the maximum economic profit when relatively calculated or even absolutely examined.

The problem is, knowing the oil rate that would be optimal since it has to be determined only by trial incrementing. And the maximum economic returns depends on the engineer's selection range of the oil rate. For this we make hypothetical assumptions to aid our investigations.

When we plot a graph of $P_{E}$ against $q_{r}$ on a Cartesian plane, the resulting plot looks like a normal distribution curve as given below in figure 1 .

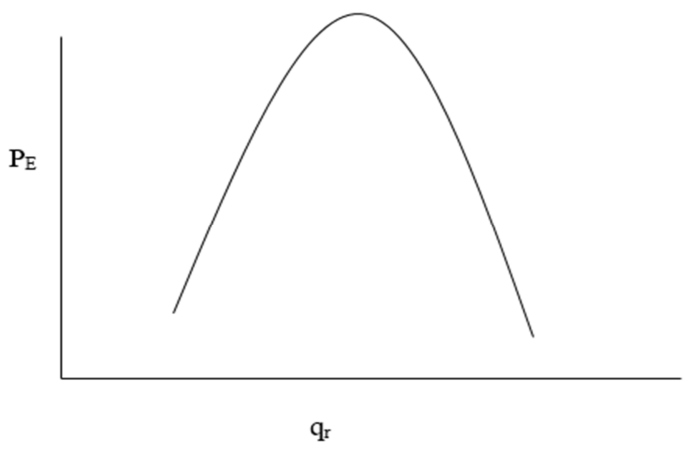

Figure 1. Schematics of the economic profit curve.

To calculate the maximum point, we have to draw two lines tangent to the two sides of the curve and extrapolate it until the tangent lines meet at a point. The point they meet is the theoretical maximum point of the profit. This point can be determined by tracing it value on the graph or from analytical deductions taking into account the direction and movements of the tangent lines. Tracing the point to the vertical side of the graph gives the value of the optimum economic profit while tracing the point to the horizontal side of the graph gives the value for the optimum oil production rate.

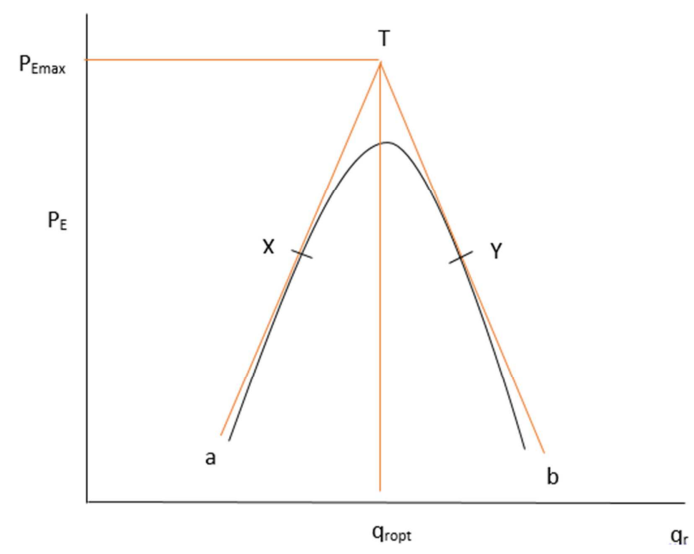

Figure 2. Determination of the maximum economic profit.

Analytical Determination of $\mathrm{q}_{\mathrm{ropt}}$.

a). Find the slope of tangent line a.

b). Find the slope of tangent line $b$.

Then PEmax is given by the relationship

$$
q_{\text {ropt }}=X+\left[\left(\frac{\text { slope } a}{\text { slope } a+\text { slope } b}\right)(Y-X)\right]
$$

Or

$$
q_{\text {ropt }}=Y-\left[\left(\frac{\text { slope } b}{\text { slope } a+\text { slope } b}\right)(Y-X)\right]
$$

When you have determined the $q_{\text {ropt }}$ then read off the value of $\mathrm{P}_{\mathrm{Emax}}$ at the vertical axis of the plot. The vertical axis value of the $q_{\text {ropt }}$ value on the extrapolated line is the $\mathrm{P}_{\mathrm{Emax}}$.

\subsection{Model Simulation}

Matlab and Excel software were used for the simulation model. The simulation took two steps.

1. The first step is the determination of the critical rate, the daily operating expense, the economic rate and the breakthrough time.

2. The second step is to use this values to further determine the optimum value of the flow rate and its corresponding optimum economic profit.

The reservoir parametres below are used for the simulation of the model. The data was gotten from an oil producing company. Name of company is not disclosed here for confidentiality purpose.

Table 1. Input data.

\begin{tabular}{ll}
\hline Parametres & Value \\
\hline Oil viscosity & $0.73 \mathrm{cp}$ \\
Oil density & $47.5 \mathrm{lb} / \mathrm{ft} 3$ \\
Porosity & 0.2 \\
Vertical permeability & $10 \mathrm{md}$ \\
Horizontal permeability & $100 \mathrm{md}$ \\
Thickness of pay zone & $50 \mathrm{ft}$ \\
\hline
\end{tabular}




\begin{tabular}{ll}
\hline Parametres & Value \\
\hline Length of perforated interval & $15 \mathrm{ft}$ \\
Gas density & $0.5 \mathrm{lb} / \mathrm{ft} 3$ \\
Radius of reservoir & $1000 \mathrm{ft}$ \\
Oil formation volume factor & $1.1 \mathrm{bbl} / \mathrm{stb}$ \\
Water density & $63.76 \mathrm{lb} / \mathrm{ft} 3$ \\
Distance from GOC to top of perforation & $15 \mathrm{ft}$ \\
\hline
\end{tabular}

\section{Result and Discussions}

From the formula for critical oil given, it was calculated that the critical oil rate is $20.17 \mathrm{stb} / \mathrm{d}$. it is given in the table 2 below:

Table 2. Table of data showing the critical oil rate.

\begin{tabular}{ll}
\hline Parametres & Value \\
\hline Oil viscosity & $0.73 \mathrm{cp}$ \\
Oil density & $47.5 \mathrm{lb} / \mathrm{cuft}$ \\
porosity & 0.2 \\
vertical permeability & $10 \mathrm{md}$ \\
horizontal permeability & $100 \mathrm{md}$ \\
thickness of pay zone & $50 \mathrm{cuft}$ \\
length of perforated interval & $15 \mathrm{cuft}$ \\
gas density & $0.5 \mathrm{lb} / \mathrm{cuft}$ \\
radius of reservoir & $1000 \mathrm{cuft}$ \\
oil formation volume factor & $1.1 \mathrm{bbl} / \mathrm{stb}$ \\
calculated critical oil rate & $20.16657 \mathrm{stb} / \mathrm{d}$ \\
\hline
\end{tabular}

\subsection{Operating Cost of the Well}

For the economic performance of the well to be properly determined, it was necessary to determine the operating expenses of the well.

The daily operating expense was determined to be $120 \mathrm{stb} / \mathrm{d}$. For the entire one year full operational period, the annual operating cost was $43800 \mathrm{stb} / \mathrm{d}$. The value of the operating cost was converted to barrel to aid us to understand the production rate at which economic returns is expected. It was from this that we concluded that the critical oil rate so determined will not yield profit. This is because the critical oil rate was calculated to be 20.17 $\mathrm{stb} / \mathrm{d}$ while the operating cost of producing it is at 120 $\mathrm{stb} / \mathrm{d}$. Producing at the critical rate will maximally delay coning but the operators would be running a loss of about $100 \mathrm{stb} / \mathrm{d}$. Since the aim of any business venture is to make profit, the operators prefer to produce at a rate above the critical rate and handle coning problems due to water and/or gas breakthrough later. The issue in the breakthrough is additional cost of production, handling and separation of the displacing phase to get the oil. Most times, there is a balance to this before the appropriate oil rate is chosen.

Table 3. Annual production corresponding to various production rates.

\begin{tabular}{|c|c|c|}
\hline Rate (stb/d) & Time to abandonment (years) & Production per year (bbls/yr) \\
\hline 2000 & 1 & 730000 \\
\hline 1500 & 2 & 547500 \\
\hline 1200 & 4 & 438000 \\
\hline 1000 & 6 & 365000 \\
\hline 950 & 8 & 346750 \\
\hline 900 & 9 & 328500 \\
\hline 750 & 10 & 273750 \\
\hline 400 & 30 & 146000 \\
\hline 390 & 32 & 142350 \\
\hline 386 & 32 & 140890 \\
\hline 385 & 33 & 140525 \\
\hline 350 & 35 & 127750 \\
\hline 300 & 40 & 109500 \\
\hline 250 & 45 & 91250 \\
\hline 100 & 120 & 36500 \\
\hline 50 & 300 & 18250 \\
\hline
\end{tabular}

\subsection{Recovery Factor and Volume Abandonment}

At first glance, operators may be tempted to produce at a very high rate. But this is at the expense of losing the well at the very early periods when most of the fluids would be abandoned in the reservoir, except in cases where pressure maintenance is planned. But for the sake of simplicity as in this research which focused on pre-breakthrough time calculation it is pertinent to ascertain the recovery factor corresponding to each choice of flowrate to see the percentage of fluid economically recoverable from the reservoir before the advent of coning which may lead to shutin of the well as in the case considered in this work.

The recovery factor is the ratio of the total fluid produced before abandonment to the oil initially in place in the reservoir.

From the table 4 below, it can be seen that for higher oil production rate, the abandonment time is less and thus the volume of fluid abandoned may be higher when compared to lower value of flow rate. 
Table 4. The recovery factor corresponding to the flowrate and abandonment time.

\begin{tabular}{lllll}
\hline Rate (stb/d) & Years to abandonment & Production per year (stb) & Total volume recovered (stb) & Recovery factor \\
\hline 2000 & 1 & 730000 & 730000 & 0.073 \\
1500 & 2 & 547500 & 1095000 & 0.1095 \\
1200 & 4 & 438000 & 1752000 & 0.1752 \\
1000 & 6 & 365000 & 2190000 & 0.219 \\
950 & 8 & 346750 & 2774000 & 0.2774 \\
900 & 9 & 328500 & 2956500 & 0.29565 \\
750 & 10 & 273750 & 2737500 & 0.27375 \\
500 & 17 & 182500 & 3102500 & 0.31025 \\
400 & 30 & 146000 & 43800000 & 0.438 \\
390 & 32 & 142350 & 4555200 & 0.45552 \\
386 & 32 & 140890 & 4508480 & 0.450848 \\
385 & 33 & 140525 & 4637325 & 0.463733 \\
350 & 35 & 127750 & 4471250 & 0.447125 \\
300 & 40 & 109500 & 4380000 & 0.438 \\
250 & 45 & 91250 & 4106250 & 0.410625 \\
200 & 50 & 73000 & 3650000 & 0.365 \\
100 & 120 & 36500 & 4380000 & 0.438 \\
50 & 300 & 18250 & 5475000 & 0.5475 \\
\hline
\end{tabular}

\subsection{Annual Profit Generated}

The annual profit generated for each flowrate within the period of time from commencement of production to breakthrough of water/ gas is given in table 5 below. When you consider the profit per year in the first year you may get a wrong choice of flowrate, this is because you have not considered the total profit throughout the period that the flowrate can support. For this case, one may choose $2000 \mathrm{stb} / \mathrm{d}$ to be the optimum flowrate since it has the highest profit per year. But the choice is found to be misleading if you consider the total profit throughout the period of production and also the economic profit of the well.

Table 5. Table showing profit per year and annual operating cost.

\begin{tabular}{lllll}
\hline Rate (stb/d) & Years to abandonment & Production per year (stb) & Profit/year (stb) & Annual operating cost (stb) \\
\hline 2000 & 1 & 730000 & 686200 & 43800 \\
1500 & 2 & 547500 & 503700 & 43800 \\
1200 & 4 & 438000 & 394200 & 43800 \\
1000 & 6 & 365000 & 321200 & 43800 \\
950 & 8 & 346750 & 302950 & 43800 \\
900 & 9 & 328500 & 284700 & 43800 \\
750 & 10 & 273750 & 229950 & 43800 \\
500 & 17 & 182500 & 138700 & 43800 \\
400 & 30 & 146000 & 102200 & 43800 \\
390 & 32 & 142350 & 98550 & 43800 \\
386 & 32 & 140890 & 97090 & 43800 \\
385 & 33 & 140525 & 96725 & 43800 \\
350 & 35 & 127750 & 83950 & 43800 \\
300 & 40 & 109500 & 65700 & 43800 \\
250 & 45 & 91250 & 47450 & 43800 \\
200 & 50 & 73000 & 29200 & 43800 \\
100 & 120 & 36500 & -7300 & 43800 \\
50 & 300 & 18250 & -25550 & 43800 \\
\hline
\end{tabular}

\subsection{The Economic Profit}

The economic profit is the adjusted and discounted profit throughout the producing period of the well. It took into account the time value of money and also the recovery factor. From table 6 below, the maximum economic profit occurs at producing rate of $950 \mathrm{stb} / \mathrm{d}$ while that for the maximum total profit occurs at a producing rate of $900 \mathrm{stb} / \mathrm{d}$. It can be seen that the economic profit yields a value closer to the optimum oil production rate. 
Table 6. Table showing the Economic profit and the total profit.

\begin{tabular}{lllll}
\hline Rate (stb/d) & Years to abandonment & Total profit (stb) & Time value of money & Economic profit (stb) \\
\hline 2000 & 1 & 686200 & 0.869565 & 43558.78261 \\
1500 & 2 & 1007400 & 0.756144 & 83410.43478 \\
1200 & 4 & 1576800 & 0.571753 & 157949.8987 \\
1000 & 6 & 1927200 & 0.432328 & 182466.8017 \\
950 & 8 & 2423600 & 0.326902 & 219778.2332 \\
900 & 9 & 2562300 & 0.284262 & 215341.2832 \\
750 & 10 & 2299500 & 0.247185 & 155599.8372 \\
500 & 17 & 2357900 & 0.092926 & 67978.86147 \\
400 & 30 & 3066000 & 0.015103 & 20282.0127 \\
390 & 32 & 3153600 & 0.01142 & 16405.2618 \\
386 & 32 & 3106880 & 0.01142 & 15996.45452 \\
385 & 33 & 3191925 & 0.009931 & 14699.12491 \\
350 & 35 & 2938250 & 0.007509 & 9864.913593 \\
300 & 40 & 2628000 & 0.003733 & 4297.202871 \\
250 & 45 & 2135250 & 0.001856 & 1627.38872 \\
200 & 50 & 1460000 & 0.000923 & 491.7605689 \\
100 & 120 & -876000 & $5.20 \mathrm{E}-08$ & -0.019963532 \\
50 & 300 & -7665000 & $6.18 \mathrm{E}-19$ & $-2.59 \mathrm{E}-12$ \\
\hline
\end{tabular}

\subsection{Sensitivity Analyses}

The following plots discuss the effect and relationship of one parameter when compared with another.

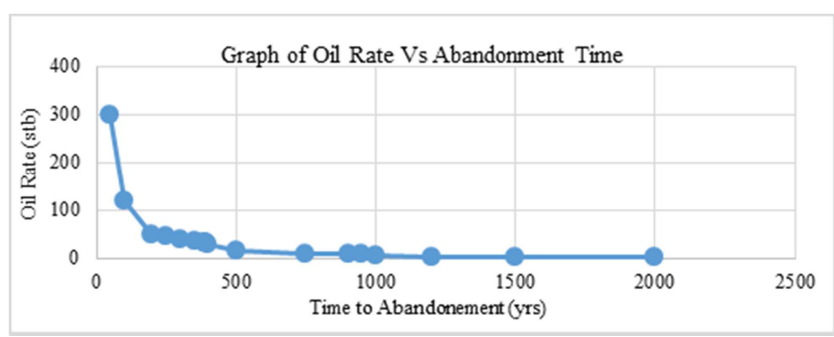

Figure 3. Graph of relationship between oil rate and time of abandonment.

From the plot above it can be seen that the abandonment time increases for decreasing oil production rate. Higher oil production rate will only support shorter periods of well life which may not be sufficient to efficiently and optimally produce the well.

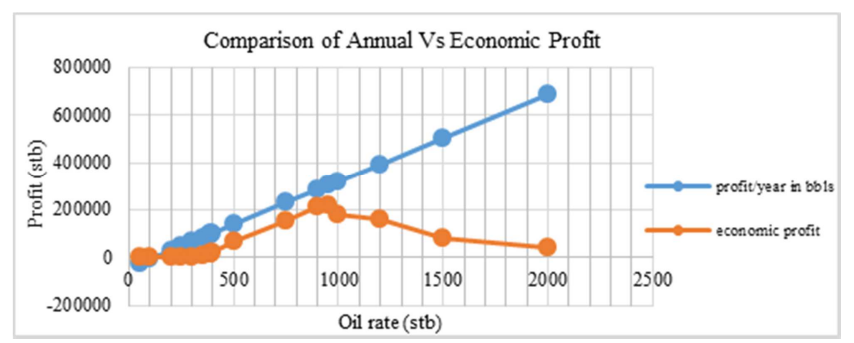

Figure 4. Comparison of economic profit and annual profit.

The plot above depicts the comparison of annual and economic profit. While the annual profit responds with a straight line for increasing oil rates, the economic profit behaves more like a bell shape normal distribution curve approaching a maximum point at its crest. This maximum point corresponds to the optimum oil production rate when traced to the horizontal axis of the graph.

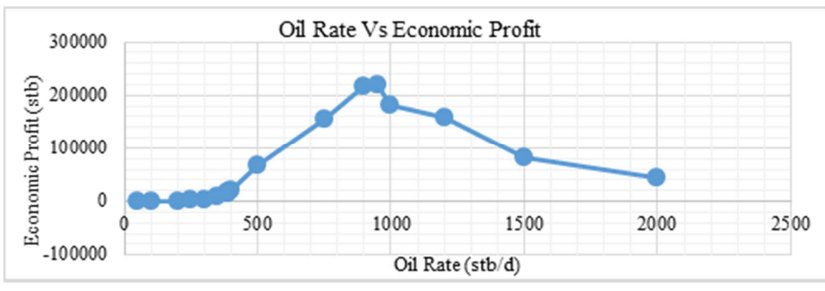

Figure 5. Full view of economic profit vs. oil rate plot.

The view of the plot of economic profit on the oil rate given in figure 5 above reveals that there is an oil rate at which the economic profit is maximum. We call that point the optimum oil production rate. To deduce this point we must trace tangents to the curve and perform some mathematical calculations. From the calculations it was determine that the optimum flowrate was exactly $918.63 \mathrm{stb} / \mathrm{d}$.

\section{Conclusions}

Extensive analyses of production in oil rim reservoirs have been conducted for Niger delta wells. The research was conducted to determine the optimum flowrate. From the results it was realized that:

i. The oil production rate affects the productive life of the well.

ii. The economic profit is an important parameter for choice of an optimum flowrate.

iii. The optimum flowrate is the rate that will yield the highest economic returns throughout the life of the well.

iv. The economic profit differed from the total profit.

v. The economic profit is the important parametres for decision making.

Also a model was developed from first principle for the calculation of the economic profit from which the optimum production rate was calculated by considering the nature of the tangents line to either side of the 
economic profit curve. From the calculations, the optimum oil production rate occurred at $918.63 \mathrm{stb} / \mathrm{d}$. This value gives us the optimum oil production rate for the optimization problem. Thus the oil critical rate which was calculated to be $20.17 \mathrm{stb} / \mathrm{d}$ was not adequate to yield economic profits from the reservoir.

\section{References}

[1] Aladeitan, Y. M, Akinyede, O. M. (2016). Optimization of Oil Rim Development by Improved Well Design. Journal of Scientific and Engineering Research, 3 (4): 169-174.

[2] Ogolo, N. A., Molokwu, V. C., Oyekonwu, M. O. (2018). Proposed Technique for improved oil recovery from thin oil rim reservoirs with strong aquifers and large gas caps. SPE189126-MS.

[3] Idoko, J. J, Saka, M, Lawal, K., (2019). Simple guidelines for screening development for oil-rim reservoirs.

[4] Ogiriki, S. O, Imonike, G. O, Ogolo, N. O, Onyekonwu, M. O (2018). Optimum Well Type for Oil Rim Reservoirs with large Gas-cap and strong Aquifer. SPE-193411-MS.

[5] Olamigoke, O, Peacock A., (2009), " First pass Screening of Reservoirs with Large Gas Caps for Oil Rim Development", Paper SPE 128603, Presented at Nigeria Annual International Conference and exhibition Abuja, 3-5 August.

[6] Ogolo, N. A., Molokwu, V. C., Oyekonwu, M. O. (2018). Technique for effective oil production from the oil rim reservoirs. SPE-193382-MS.

[7] Obidike, P., Oyekonwu, M. O., Ubani, C. E. (2019). Exploitation of the thin oil rim with large gas cap-critical review.
[8] Amoni, N., Molokwu, V., Oyekonwu, M. (2017). Proposed Technique for improved oil recovery from thin oil rim reservoirs with strong aquifer and large gas caps. SPE189126-MS.

[9] Keng, S. C, Azmukiff, M. K, Nasir, D (2012), "Breaking Oil Recovery Limit in Malaysian Thin Oil Rim Reservoirs: Water Injection Optimization. SPE14157 Presented at the international Petroleum Technology Conference Bangkok. 7-9 March.

[10] Uwaga, A. O and Lawal K, A (2006). "Concurrent Gas-cap and Oil Rim Production", SPE 105985 presented at the 30th Annual Technical Conference and Exhibition Abuja, Aug 1-2.

[11] Bourenane, M., Tiab, D and Recham, R. 2004: "Optimization of Perforated Completions for Horizontal Wells in a HighPermeability, Thin Oil Zone-Case Study: Hassi R'mel.

[12] Silva, J. M. D. and Dawe, R. A. (2010). The Challenge of Producing Thin Oil Rims in Trinidad", The West Indian Journal of Engineering, 32, 36-41.

[13] Onyeukwu, I. H, Peacock, A., Matemilola, S. A (2012), "Improving Recovery from Oil Rim Reservoirs by Simaultaneous Gas and Water Injection", Paper SPE 162956, Presented at the Nigerian Annual Technical Conference and Exhibition Abuja, 6-8 August.

[14] Lyare, U. C. and Silva, J. M. D. (2012). Effect of Gas Cap and Aquifer Strength on Optimal well Location for Thin Oil Rim Reservoirs", SPETT Energy Conference and Exhibition, SPE 158544 .

[15] Maroua Jeoua (2019). Optimisation of oil production in an oil rim reservoir using Numerical simulation with focus on IOR/EOR application. SPE-196709-MS. 